\title{
EL MATRIMONIO DE ENIDE
}

\author{
J.E. Ruiz-Doménec
}

A mediados del siglo XII, mientras la caballería ganaba terreno entre los grupos dominantes, la institución matrimonial acusaba un serio quebranto. La situación llegó a ser verdaderamente grave. Algunos escritos fechados a principios de la década de los cincuenta testimoniaron la importancia de la crisis. Mas tarde, y en medio de una extraordinaria inflexión poética, el tema del matrimonio se presentó como un elemento primordial en la llamada literatura de Bretaña.

Este es el objeto del presente fragmento: la manera cómo los novelistas percibieron la crisis matimonial en el norte de Francia a finales del siglo XII. Una manera - deberé confesarlo de entrada - vibrante y enérgica. Pero no todo fue por ideología. Los recuerdos familiares contribuyeron sin duda a marcar la línea de esa percepción y cargarla de significaciones profundas e incluso misteriosas. Algunos jóvenes, como Perceval, supieron de labios de sus primas terribles secretos, ignorados hasta ese momento, de! pasado de sus adoradas madres. La memoria se convierte en ocasiones en la desencadenadora del drama. Pero el conflcito moral comenzó mucho, muchísimo antes...

El sistema de parentesco feudal es patrilineal. Esto significa que un niño pertenece automáticamente al linaje de su padre. Cada uno de estos linajes posee un stock de hombres y de mujeres que son propios de él. El matrimonio es la forma habitual del intercambio y de la alianza. La versión más acabada $-\mathrm{y}$ sin duda la más acorde con la ley de selección del parentesco forjada a finales 
de siglo X-consistió en el ejercicio de un matrimonio preferencial con la prima cruzada matrilateral ${ }^{1}$. En este tipo de matrimonio, los siblings de un linaje fijaban el destino de una de sus mujeres (hermanas e hijas) y la donaban en sentido descendente a algún pariente cercano (con inclinación al hijo de la hermana del jefe del linaje superior). De este modo se acentuaron los rangos en. tre dos grupos de filiación y sobre todo las relaciones de dominio de los hombres sobre las mujeres.

$\mathrm{Ni}$ ambiciones ni honores macularon esta estructura de organización matrimonial y la ley del parentesco en la que se asentaba. Los varones completaron sus acuerdos mediante pactos privados. de hombre a hombre, homenajes de vasallaje, que en el fondo eran simples principios de reciprocidad. Las mujeres, por su parte, se convirtieron en preciosos objetos de intercambio. Este era realmente su gran valor dentro de la sociedad feudal, aunque también la naturaleza de su terrible humillación. Durante más de doscientos años, los aristócratas, inspirados en una moral particular, doblegaron el orgullo femenino a partir del ejercicio de estas prácticas matrimoniales; el orden de domianción de los hombres sobre las mujeres fue el principio rector de tales acciones.

El amor alteró estas concepciones del parentesco. En un primer momento su imagen fue inocente, aunque dramáticamente trágica como en el caso de Guilhem, el duque-trovador ${ }^{2}$; más tarde llegó a demoler las leyes de selección, las prácticas matrimoniales y la propia definición del parentesco, La Iglesia estaba detrás de tales planteamientos, sosteniéndolos y avivándolos. La moral de los clérigos se opuso desde un principio a la moral de los guerreros 5 . Los múltiples reproches que obispos y clérigos hicieron sobre la práctica matrimonial feudal fue algo más que una sombra. A lo largo del siglo XII - y especialmente en el seno de la corte dominada por los príncipes y los reyes - se alzaron voces convencidas de la peligrosa tendencia endogámica del matrimonio feudal. Los moralistas más severos estaban de veras convencidos de que muy pronto se llegaría a una formulación diferente de las normas que

1 J.E. RUiz DOMÉNEC, eLa primera estructura feudal en Quaderni Catanesi di Studi Classici e Medievali, IV, 8, 1982, pp. 301-368.

2 J.E. RUIZ DOMENEC. Amor y moral matrimonial: El restimonio de Grilhem de Peitieu, Bellaterra, 1983 (Monografias de Medicvalia, núm. 3).

${ }^{3}$ G. DuBY, Le Chevalier, la Femme ef le prêtre. Le Mariage dans la France Féodale, Paris, 1981. 
regían el matrimonio en la sociedad. El esfuerzo traspasó las nebulosas de la predicación y llegó a formar parte del verso más importante de esta época: el verso de la novela artúrica. El poder embriagador de la corte permitió forjar nuevas conductas, renovadores principios de rectificación de la naturaleza racial o extraños roles de adopción donde los seniores actuaban con mayor libertad y generosidad con respecto a los «jóvenes», sus hijos o sus sobrinos. La consanguinidad espiritual sustituyó a la biológica y de ese modo un señor, o mejor aún el propio rey, favorecía el destino de un joven, errante primero, pobre maś tarde, bastardo finalmente, e inmediatamente después de investirle caballero le concedía la mano de alguna de aquellas doncellas tristes, sometidas a pérfidos dragones o a encantamientos tenebrosos. Era un recurso inocente en cierto modo, aunque debajo de esa superficie dorada se encontraban profundas y sólidas raíces morales. La literatura cortés forjó un modo de contraer matrimonio alejado de las peligrosas tendencias endogámicas de los feudales. El incesto era el mal por excelencia. No les importó que alguno de estos jóvenes caballeros - los más intrépidos, abnegados y hermosos - terminaran en el lecho de alguna mujer casada, aunque fuese la mismísima reina Ginebra. El adulterio fue una simple licencia poética. No socavó en ningún momento la moral matrimonial de la Iglesia.

Al final de todo, se desarrolló una fuerte rectificación de los principios de la privatización, de la aconvivialidad», donde los acuerdos más duraderos se establecían entre los proximi, entre los amici, que en último término formaban los siblings de dos grandes linajes -individuos de la misma sangre, con los mismos antepasados, con santuarios comunes y con un mismo código de conducta, desarrollada en la literatura genealógica, verdadera cobertura ideológica del sistema de parentesco ${ }^{4}$. La crisis despertó a los jóvenes. Muchos de ellos - los más intrépidos y audaces, como Erec, Yvain y los demás - buscaron en la aventura el modo de obtener esposa como sus padres y sus abuelos lo habían hecho en la ley de selección del parentesco feudal. En efecto, para estos últi-

4 Cfr. G. DuBY, «Remarques sur la littérature génealogique en France aux XI et $\mathrm{XII}^{\circ}$ siècles». en Hommes et Structures du Moyen Age, París, Mouton, 1973, PP. 287-298. K. HAUCK. sThe literature of houese and kindred associated with medieval noble families, illustrated from eleventh and twelfth century satires, of the nobility, en Tbe Medieval nobility. ed. T. Reuter, Amsterdam, 1979, pp. $61-103$ 
mos se cumplió a lo largo de decenas y decenas de años la célebre tesis de Claude Lévi-Strauss, según la cual sel matrimonio entre primos cruzados no sólo es autorizado sino obligatorio. Es obligatorio desde el momento en que es posible, porque proporciona el sistema de reciprocidad más fácil de concebir»s. Pero, desmoronado desde dentro ese sistema de intercambio que conducía segúnlos ideólogos de la Iglesia a uniones claramente incestuosas, toda la sociedad cortés se lanzó a un tipo de matrimonio exogámico, lejano, «donde se desarrolla un ciclo más complejo y en consecuencia más frágil y cuyo final es más incierto» ${ }^{6}$. A finales del siglo XII, y coincidiendo con la eclosión de la novela cortés, la nueva forma de buscar esposa se entendió como un progreso social, al mismo tiempo que como una hermosa aventura.

Consideremos un ejemplo. Lo tomo directamente de un roman de Bretaña: el Erec de Chrétien de Troyes? . No son simples fantasías las cosas aquí narradas. Existe algo más. Tratemos de verlo con alguna detención. Esta novela - escrita con toda probabilidad sobre $1170^{8}$ - debe considerarse como un intento consciente de oponerse a las prácticas matrimoniales feudales y de encontrar una solución al fenómeno matrimonial estrechamente ligado con la aparición del nuevo espacio social, político e imaginario de la corte y con la fijación definitiva de la figura del rey. El mensaje novelesco es la confirmación de posturas ya conocidas, procedentes la mayor parte de los moralistas de principios de siglo que, $\sin \mathrm{em}-$

5 Cfr. Lévi-Strauss, Les structures élêmentaires de la parenté, París, 1949. Sobre la sociedad feudal cfr. J.E. Ruiz DOMENEC. Système de parenté et theorie de I'alliance dans la société catalane (env. 1000, env. 1240), en Revue Historique. 532, 1979, pp. 305.326.

${ }^{6}$ LEVI-STrAuSS, op. cit., p. 85 (trad. española). Sobre el significado de tales acciones en el interior de la sociedad cortés cfr. J.E. RUIZ DOMÉNEC, El laberinto cortesano de la caballeria, Bellaterra, 1980 y 1981 (Monografias de Medicvalia, núm. 1 y 2).

7 Utilizaré la edición de W. Foerster, Kristian von Troyes, Erec und Enide, Halle, 1934. El lector puede seguir la narración novelesca en la traducción de esta obra realizada por C. Alvar y V. Cirlot para la Editora Nacional, Madrid, 1982.

8 Cfr. A. Fourrifr. encore la chronologie des ocuvres de Chrétien de Troyes», en B.B.I.A.S., II, 1950, pp. 69-96. 
bargo, habían fracasado entonces por su peculiar y ácida actitud ante el mundo aristocrático.

Pero, tras varios decenios de tensiones en el interior de la buena sociedad francesa y anglo-normanda, terminó por reconocerse que la elección de un nuevo sistema matrimonial era el cauce natural para la aceptación de un fenómeno mucho más complejo: la propia intromisión de los valores de la caballería en el mundo aristocrático. La obra de Chrétien se ligó abiertamente a este gigantesco esfuerzo y si su esteticismo punzante convierte a muchos de sus-aspectos en un recurso crítico e irónico, se debe más a la idea del ca. rácter irrefrenable de los nuevos valores que a la sensación de fracaso de la sociedad. La práctica matrimonial está presente en toda su obra. Fundamentalmente al principio?

Erec es una obra de juventud ${ }^{10}$. Chrétien tuvo éxito con ella, pues los elementos literarios de la materia de Bretaña no estaban aún desgastados por el uso corriente. El novelista se anticipa a las novedades de su época y presenta un proyecto social. El cambio operado a lo largo de sus novelas, conduce su problemática de los tonos melódicos y desgarrados de su Chevalier de la Charrete al carácter marcadamente adistantes, constructivo, de su Li Contes del Graal" ${ }^{\prime}$. La poesía de Chrétien se reduce sin embargo en el Erec a presentar una serie de elementos simples, confiando en que la sola enunciación de ellos, convierta su discurso poético en un desencadenador de pasiones y un elemento reformador de las conductas - naturalmente, de las conductas feudales.

El matrimonio es el objetivo fundamental. La poesía se ve reducida al ámbito doctrinal en el que, de forma progresiva y sin reservas, se introducirán los elementos del nuevo orden en las prácticas matrimoniales. El cambio detectado por Duby hacia 1150, alcanza plena significación y cordura poética en 1170 cuando el público cortesano escucha atentamente «la aventura del Ciervo Blanco» con la que Chrétien da comienzo a su primera novela de asunto artúrico $^{12}$.

${ }^{9}$ La última actualización con inmejorable estado de la cuestión en P.S. NOBLE. Love and Marriage in Chrétien de Troyes, Cardiff, University of Wales Press, 1982.

${ }_{10} \mathrm{~S}$. HOFER, Chrétien de Troyes, Leben und Werk, Köln, 1954 pp. $59 \mathrm{~s}$.

11 Sobre el sentido de la evolución W. KeuERMANN. Ausbaussil und Weltbild Cbrestiens von Troyes im Percevalroman. Tubingen, 1967 (12 ed., 1936), pp. 4-5.

12 Sobre el público de estos romans, cfr. P. GaLais, «Recherches sur la menta- 
La aventura conduce al protagonista, a Erec, hijo del rey Lac - uno de los primeros caballeros de la Tabla Redonda - a un l $u$ gar: el impulso desencadenador de la acción es internamente caballeresco. Erec persigue a un caballero traidor y a un enano. Ambos habían insultado gravemente a la reina Ginebra, provocando un escándalo, en cuya solución los caballeros deben estar prestos y entrar en juego. El deslizamiento del protagonista hacia el lugar de la acción es síntoma inequívoco de esa tendencia de la pasión novelesca por no dejar nada al margen de la ideología monárquica y del espacio cortesano. El comienzo produce una sensación de pérdida de naturalidad, por eso el arte reacciona. Tras las brumas de los valores internamente literarios (y poéticos) se elevan programas rígidos de ordenación de la sociedad. El desplazamiento de Erec, desde la corte del rey Arturo hasta el lugar de la acción, busca disminuir la distancia existente aún hacia 1170 entre la corte monárquica y los segmentos territoriales dominados por aristócratas celosos de sus derechos y privilegios, resistentes y rudos individuos que pretendían mantener incólume un mundo a punto de desaparecer. La novela reduce la vergonzosa diferencia entre los valores corteses y la situación del mundo aristocrático por medio de un tácito y subjetivo planteamiento: la solución a los males de la época deberá ser resuelta mediante la introducción de los aristócratas en el seno de los valores monárquicos y en la aceptación de los principios impuestos por el espacio cortesano. He aquí la base subjetiva de la inclusión del caballero Erec en el lugar donde, espacial y humanamente, las cosas superan la singularidad de cada dato para inscribirse en la exigente repetición de un fenómeno de estructura. El arte de la novela es la respuesta definitiva a tal percepción del mundo pues pone de manifiesto a las claras las transformaciones sociales acaecidas y que aún no han hallado expresión en la sensibilidad de los aristócratas territoriales. La modificación exige trasladar el acto repetitito de lo concreto al mito, poniendo en claro también aquí que - como dice Daniel Poirion- ala litté-

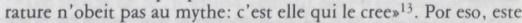
lugar de la acción debe verse como un espacio totalizador de la an-

lité des romanciers français au moyen âges en Cabiers de Civilisation Médiévale. VII, 1964, pp. 479-493, XIII, 1970, pp. 333-347.

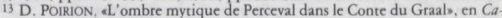
hiers de Civilisation Médiévale, XVI, 1973 PP. 191-198. La cita p. 195. 
terior estructura, la feudal, cuya estrategia matrimonial va a ser puesta en tela de juicio.

El proyecto de Chrétien es aún apasionado y algo ingenuo, pues se deja fascinar por la tentación de sublimar estéticamente los actos de su héroe (frente a lo que hará más adelante, entre 1177 . 1181, con Yvain, el protagnista del Chevalier au Lion). Hegel llamó a esta actitud «libertad hacia el objeto» y deslizamiento hacia la sensibilidad romántica ${ }^{14}$. Efectivamente, Erec se dirige hacia el lugar de un modo espontáneo, apofántico, como si una manifestación irrepetible se tratase. El destino le aguarda con una aureola extraña que nace del contacto directo de la novela con las exigencias más acuciantes de la sociedad de su época. El auditorio comprenderá de inmediato el significado y el valor de «ese» lugar. De la mano de esta comprensión es fácil hacer un análisis minucioso de los condicionamientos sociales del desmoronamiento allí contemplado: un análisis, pues, del grado y el nivel de recepción de lo concreto que lleva en su seno la obra literaria, en especial la novela de Bretaña ${ }^{15}$.

El caballero Erec, en su deslizamiento desde la corte del rey Arturo hacia el exterior, llega a un castillo (chastel) mout bien seant et fort et bel (v. 346), en cuyo interior se celebra una fiesta, expresión de un fenómeno - que nosotros sabemos que es estructural. Desde el castillo del valvasor se comprende la realidad de este mundo, ajeno a la corte. El lugar está dominado por un conde, el senior loci, cuya hermana está casada con un pobre valvasor. La hija de ambos es naturalmente sobrina matrilateral del conde. Así la estructura inicial del sistema de parentesco feudal aparece perfectamente delimitada:

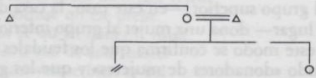

Nadie duda que los valores poéticos modifican la presentación de la estructura de parentesco que rige en aquel lugar donde ha

14 G.W.F. Hegel, Aestbetik, ed. F. Bassenge, Berlin, 1955.

is Para una teoría de la recepción, ffr. H.R. JAuss, Aesthetische Erfahrung und literarische Hermeneutik, Munich, 1977. 
llegado Erec; pero, tras los tonos melódicos de la descripción, comienza a desarrollarse el sentido de ese fenómeno cultural tal como se contemplaba por la sociedad hacia 1170 . Una vez más la novela se hace presencia objetiva, aunque mediatizadamente, de una realidad concreta, cuya exigente tensión busca ser desvelada por la buena sociedad (que es naturalmente el público directo e inmediato de la novela cortesana) ${ }^{16}$.

Conviene ilustrar un poco más este fenómeno. Chrétien ofrece un rico material al historiador social, siempre y cuando éste sepa interrelacionar estrechamente los datos sugeridos en la novela en un sistema coherente y explícito. En esta ocasión se expone de un modo sencillo, y naturalmente ameno, la realidad estructural del sistema de parentesco feudal. Êsta descansa, como vemos, en una red de complementariedades, entre el señor del lugar (el conde) y el guardián del lugar (el valvasor), que ha sido trazada mediante la entrega de una de las mujeres de la casa del señor, del conde (en este caso, su propia hermana) a su vasallo. La unidad de la tierra se identifica con este conjunto de ensamblamientos en el contexto de una tradición. Esa tradición es algo aún vivo hacia 1170, pero en crisis. La novela es testigo principal de esta transformación. En cualquier caso, el historiador social deduce algunas consecuencias de este fenómeno. Las limitaré a tres; $1^{2}$ ) La relación triangular entre el señor de un lugar y el guardián del lugar pasa por la entrega de una mujer, confirmándose así el siguiente fenómeno: si un aseñor» debe tratar con un hombre de fuera de su familia, mejor será convertirlo, cuando menos, en su yerno, o en su cuñado (según entrege la hija o la hermana); y, aspirando a repetir el acuerdo, transformar al futuro pretendiente de su hija, en su sobrino o su primo; $2^{2}$ ) Las mujeres van en un sentido descendente de la escala social. El grupo superior - en este caso, la casa del conde como señor del lugar- dona una mujer al grupo inferior, la casa del valvasor. De este modo se confirma que los feudales son estrictamente hablando edonadores de mujeress y que los grupos donadores son jerárquicamente superiores a los grupos receptores; $3^{2}$ ) La necesidad de proseguir con el sistema, dando pie con ello a un acto de revitalización general de la comunidad, asegurando la

16 Cfr. P. Gaunis, ¿Littérature et Médiatisation, reflexions sur la genèse du genre romanesque», en Etudes littéraires I, 1971, pp. 39-73. 
unidad del territorio al margen de las organizaciones gentilicias o de las administrativas ${ }^{17}$.

La novela avanza desmenuzando las circunstancias de lo concreto y trata de conjugarlas con los proyectos imaginarios. Pero el argumento novelesco (e incluso su intriga, aquí simplemente esbozada) tiene además, como carácter complementario, el ser algo así como una seducción hacia el público de las perversas intenciones de la ideología dominante, en el caso matrimonial, la de los moralistas de la Iglesia. La técnica literaria de Chrétien siempre es anticipación de contenidos. Así, el valvasor indica de entrada a Erec una cierta limitación de la realidad del lugar. Esta delimitación muestra a las claras la situación objetiva de la realidad social del mundo aristocrático en la séptima década del siglo XII. El lugar está dominado por un equívoco extraño (probablemente el miedo a la repetición estructural) pues el valvasor considera injusta la pobreza que le aflije a él y sobre todo a su bellísima hija. La singularidad de la confesión al caballero Erec indica que no está dispuesto a aceptar el destino (que en realidad son las normas del sistema de parentesco) y entregar a su hija a un grupo de filiación inferior al suyo. Tampoco quiere enfrentarse con el senior loci, el conde. La coexistencia y la complementariedad del conjunto territorial está en crisis, pero ambos se resisten a poner fin a ella y dejarse deslizar al orden político y administrativo de las monarquías en ascenso. Con otras palabras, el valvasor no está dispuesto a aceptar la autenticidad de la costumbre $\mathrm{y}$ asentar en ella el destino de su hija, que reconoce es sobrina del conde, pues su esposa es hermana de él, y así lo dice:

\author{
Et neporquant bien fust vestue. \\ Se sofrisse qu'ele preïst \\ Tot ce qu'an doner li vossit. \\ Nes li sire de cest chastel \\ L'eüst vestue bien et bel \\ Et si li feist toz ses buens; \\ Qu'ele est sa niece, et li est cuens (vv. 518-524)
}

El ocaso de un sistema social como el feudal (que había previsto

17 J.E. RUIZ DOMÊNEC, «Structures de parenté et rapport de productions, en Actes Colloque, Production. Pouvoir. Parenté, Paris, 1980. 
auténticamente los más mínimos detalles de la práctica matrimonial) se pone a la vista del público. El pobre valvasor rompe con el principio de la reciprocidad que era connatural al acto del vasallaje y del acuerdo ${ }^{18}$. La fidelitas era compensada con la cura. Pero, este rudo individuo no quiere apoyarse en la confianza de su señor, el conde, para salir de su indigencia, de su amarga pobreza. El equilibrio de la privatización de las funciones materiales, sociales o culturales parece estar tocando fin. La ausencia del valvasor del lugar, entregado a guerras lejanas - en la periferia del Occidente, probablemente al servicio del conde y de esa exigencia del sistema feudal por conducir periódicamente la acción militar fuera de las fronteras de la Cristiandad-es, en primer término, la culpable de su situación ${ }^{19}$. Bien es verdad que las condiciones hacia 1170 empezaron a traer consigo por de pronto un movimiento de retroceso del equilibrio interno en el seno de los señoríos territoriales. El valvasor recurre para solventar su ruina económica y, simultáneamente, para ofrecer un abuen» partido a su bellísima hija, a un principio totalmente «moderno», cortesano y monárquico: entregará a su hija a un futuro epoćtico», será del caballero vencedor en la aventura del gavilán. Una apuesta decisiva. Trasciende por sus solas fuerzas al carácter de la máquina feudal y al principio de la privatización. Por encima del conde, y más allá de él, está el rey. Sobre su orden quiere descansar el destino de su hija. La novela da esperanza en un futuro mejor bajo la sombra monárquica. Los segmentos territoriales se dejan seducir por la política administrativa procedente de la corte. Los ministeriales convencen a los guardianes de los territorios de la necesidad de aceptar la soberanía del rey. La novela guía estos intereses. Los intereses de los «señores* cortesanos, los príncipes y los reyes, los verdaderos $-\mathrm{y}$ únicosmecenas $^{20}$.

Pensemos por un momento en la «aventura del gavilán». En su conjunto Chrétien quiere mencionar con ella algo sumamente complejo: 1) La nueva moral matrimonial, impuesta por los clérigos y los obispos, ya que el matrimonio, a partir de ahora, no será el resultado de una norma de parentesco, sino el premio a un ven-

18 M. Bloch, La Société Feodale, París, 1968, pp. 219.223.

19 J.E. RUIZ DOMENEC, «Guerra y Agresion en la Europa Feudals. Quaderni Catanesi di Studi Classici e Mediaveli, 11, 3, 1980, pp. 265-324.

$20 \mathrm{~J}$. BumKE, Mäzene im Mittelalter, Munich, 1979. 
cedor en una aventura de contenido caballeresco; 2) La nueva imagen de la mujer dentro del espacio cortesano. La hija del valvasor aparece como un objetivo superior. Una doncella - naturalmente virgen-, rubia y hermosa, como un sueño, blanca - cómo no- y cuya fascinación incita a los «jóvenes» caballeros a participar en la aventura; 3) El matrimonio termina siendo en definitiva el resultado convergente de dos elementos, definidos ambos por la noción de juego. Estos tres fenómenos son simultáneos y se apoyan en la crisis del sistema feudal.

La recepción de tales acontecimientos en el público que oía las novelas de Bretaña alcanza diversos acentos entre los cuales hay que destacar - por su especial implicación dentro de la práctica matrimonial - la aceptación de que los pasos dados por el caballero Erec en busca de la hija del valvasor (cuyo nombre aún desconocía el auditorio - ¿era necesario? - ) no son puramente elementos novelados, sino fenómenos históricos en un sentido-estricto. El arte de la novela se convierte así en una hechura amplísima de los nuevos valores cortesanos porque responde a una necesidad social inmediata. Este impulso seguirá adelante mientras sea efectivo y alcance el valor de ordenación social; es decir, mientras se perciba en él la juiciosa búsqueda de una nueva forma de desarrollar las estrategias matrimoniales y se anulen los valores de un sistema estructural, peligroso y quizás inmoral (la moralidad es aquí el resultado de una reflexión eclesiástica), que durante siglo y medio había organizado la comunidad europea. Por eso, en el Erec, primera novela de Chrétien, el matrimonio es el fenómeno más importante hasta el punto que, confirmando la tesis de Georges Duby, sapparait en position maîtresse, au coeur d'une image de la société parfaite ${ }^{21}$. Y así es como el fenómeno descrito por Chrétien en la *aventura del gavilán» es en sentido estricto un fenómeno histórico, aunque recubierto y fundamentado en el artilugio de la poesía, es decir, en un dominio esencial del comportamiento humano.

Naturalmente, las creaciones imaginarias -Adorno lo ha dicho $^{22}$ - son modificaciones de lo empíricamente presente. Su objetivo es presentarnos algo que no es empírico como si lo fuera. $\mathrm{Y}$ no le resulta difícil, pues el origen lejano de todo es ciertamente

21 G. DUBY, op. cit., p. 23.

22 TH. V. ADORNO, Aestbetiscbe Theorie, Frankfurt, 1970. 
lo empírico. Para el arte de la novela de Bretaña, y en especial para Chrétien, hay que tomar en serio la situación real (pero en lo concreto) de una época para poder implantar la nueva situación real (pero en lo imaginario). Este desplazamiento se consigue mediante el esfuerzo colosal del protagonista, en este caso del caballero Erec, cuya actitud arrogante ante los problemas de su momento le permirirá profundizar en la narurajeza ufalsa» del núcleo del parentesco feudal y, de ese modo, colaborar en su definitiva destrucción. Todo ello además vendrá acompañado de la búsqueda de un orden matrimonial nuevo; y, concretamente para él de una esposa lejos del círculo de relaciones de su linaje (rechazando así la posibilidad de contraer matrimonio con alguna de sus «primas», de las mujeres con las que habitualmente tenían relación su familia).

Este bello programa comienza a seducir al mundo cortesano y caballeresco. La «aventura del gavilán» pone a prueba, por primera vez en la historia (y fue en la esfera imaginaria) la materia de la caballería como imagen del mundo. Este es el riesgo sublime de esta novela. Los caballeros cortesanos, los muy nobles pares del rey Arturo, experimentan el nuevo poder de un modo absoluto. Necesitan arrebatar las doncellas de las garras de los «señores» territoriales, sus tíos y sus primos, para alejarlas del gran peligro, de la cópula maldita, del matrimonio en un grado prohibido de consanguinidad, e incluso del incesto. El ser de la caballería esencializa el mundo a partir de su capacidad para hacer posible una expresión de este tipo. El juicio moral no trata de infravalorar la fuerza de los «señores» feudales, pero los sitúa en una posición de antipatía ante el público, registrándose así los valores apologéticos de la nueva institución impulsadora de estos valores, la Iglesia episcopal. Este hecho configura de entrada la actitud de Erec. Un buen caballero, lozano, fiel a los principios emanados de la corte y, en concecuencia, a la ideología de la Iglesia. La caballería se hace a golpes de esfuerzos sublimes. La eaventura del gavilán está llena de un coraje áureo, ascendiendo hacia las cotas más elevadas de lo que Reto R. Bezzola denominó un proceso de iniciación ${ }^{23}$.

En definitiva, el fortalecimiento del valor caballeresco va a ser modelado por la ejecución artística de su modelo de conducta en la novela de Bretaña. Erec alcanza en la batalla judicial (en el $i u d i$ -

${ }^{23}$ R.R. Bezzola, Le sens de l'aventure et de l'amour, París 1968, pp, 92 ss. 
cium Belli) el objetivo que busea (la mano de la hija del valvasor), asegurando por añadidura el nuevo orden cortesano y monárquico en ese lugar. La alteración alcanza pleno significado. En el orden feudal, las mujeres iban de arriba hacia abajo de la escala social. En esta línea, la hija del valvasor estaba destinada - ¿y también condenada? - por uso y sistema a ser *donada» a un guerrero, a uno de esos acastellanos», guardianes de castillos y ejecutores en último término del orden feudal, tercer elemento de la escala social: primero, el conde; luego el valvasor; finalmente, este guerrero, cuya existencia era necesaria. La realidad de este destino explica hasta cierto punto la actitud de esta mujer a lo largo de la novela: su obligado silencio y su situación de inferioridad ante el oscuro malestar percibido en su héroe, esposo y señor. La ahija del valvasors - la bella y adorable Enide - sabe que respetando lo nuevo, lo moderno - aunque sea ligándose a la trivialidad que supone limitarse a acompañar insensatamente a su esposo en la errancia en busca de su cređito como caballero alcanzará pleno sentido su existencia. Exiliada de su tierra, falta de coherencia en sus actos, la seducción dura mientras siga existiendo ese impulso humano, frágil e inútil, llamado desde entonces amor. Pero, ¿qué clase de amor?. La Iglesia drásticamente dejo una cosa clara: frente a la pasión impetuosa del adulterio, o del inceso, sólo el amor santificado en el sacramento del matrimonio (la caritas) puede alcanzar pleno florecimiento en la conducta de los hombres ${ }^{24}$.

Pero, después de todo Chrétien es un novelista. No puede hablar del tema matrimonial de un modo tan prosaico. Tal vez la evocación de la aventura sirvió para manifestar el secreto oculto en el interior de una novela. Erec ha triunfado sobre las furzas irracionales, titánicas y adversas que ha encontrado en el interior del bosque. Una especie de iniciación que muy bien puede deberse a la fuerza del atavismo de la materia que se adapta pero que en el fondo asemeja ese peculiar instinto de conservación que permite sobrevivir en el interior del mundo cortesano. Un caballero, cabal como él, no puede hundirese en estos simples detalles. La corte sale en su defensa. La ficción literaria coloca boca abajo la realidad

24 G. Duвy, De l'Amonr an XIle siècle, París, 1981. 
social de la época. Pero eso es normal. Todos soñamos alguna vez con ese placer misterioso y encantador de enamorar a una doncella, pobre, de exquisito gusto $-y$ de bella piel-y que sin demasiada dificultad, por una especie de encantamiento social, se convierta en una princesa. ¿Era ese el destino que le esperaba a la pobre Enide?.

Tengo que confesar algo. El título de este trabajo habla del matrimonio de Enide, no del de Erec. El mundo cortesano, aunque lo buscó, no consiguió liberar a la mujer del dominio del hombre. Para ellas la espera consistía en la llegada de algún apuesto caballero de la Tabla Redonda. Al mismo tiempo, temían por su salud física, y su virginidad naturalmente, en la casa de sus padres. Los hermanos o cualquier pariente masculino, acechaba entre los silencios nocturnos. Estas mujeres de finales del siglo XII libraban una doble batalla: interior la primera, en el vano intento de conservar la blancura de su piel y la tersura de sus senos, manteniéndose incólume para el matrimonio. Exterior, más tarde, pues el destino echó en su contra un fuerte desfase entre ambos sexos. La tasa de masculinidad aumentó al disminuir el número de hombres con respecto al de mujeres. ¿Y qué era una mujer no casada en esta sociedad cortesana, dominada a pesar de todo por el hombre? El amor barrió la ley del parentesco feudal, pero no el dominio del hombre sobre la mujer. El progreso social de la exogamia, y la conversión de la aventura en la estrategia matrimonial, no impidió que fueran los hombres los ejecutores del plan. Un aciago destino se introdujo penosamente en estas doncellas. Chrétien por la fuerza de su ficción novelesco salvó a Enide de ese aprobio. Veamos cómo.

Erec la conduce a la corte del rey Arturo. Aún le brillaban los ojos por la pasión seductora. La propuesta matrimonial con Enide se realizará lejos de la casa del padre. Ella es pobre, no tiene ancestros ilustres, carece de linaje. Pero su belleza eclipsa momentáneamente estos inconvenientes. Chrétien se entretiene en describir esa textura especial del físico de Enide. Trata con ello de convencer a su auditorio para que acepte lo ilógico del caso. Un joven caballero, errante en busca de fortuna, se decide por una mujer que no es por el momento princesa. Pero la atormentadora belleza de Enide hace las veces de reclamo social. Sus ojos o sus senos exhalan lo que no tiene su padre o sus hermanos. No hay dote, ni señorío territorial que la legitime. Pocos en el interior del mundo cortés 
en la séptima década del siglo XII iban a creer ese caso. El amor no puede con todo. Menos con la fabricación de la riqueza. ¿Quién puede nutrir al nuevo matrimonio? ¿Quién puede rectificar el orden que a todas luces es injusto? Lo es, ciertamente, porque Enide luce mejor que cualquiera de las princesas de verdad que viven en la corte del rey Arturo. Ser y parecer. Dos cualidades diferentes. ¿Cuántas ruinas morales y físicas no han tenido lugar desde este momento - sobre 1170 - cuando los hombres han confundido el ser de una mujer con su parecer?

Erec llega a la corte. Se sitúa junto al rey y a la reina. Los tres van cogidos de la mano. Forman un triángulo perfecto. Falta el cuarto elemento, la tetrametría necesaria para el rito definitivo. Erec confiesa en público su intención de casarse con aquella bellisima doncella. La encomienda a la reina (je vos amain, v 1554). Explica su situación y sus intenciones.

ne por biauté ne por lignage

ne doi je pas le mariage (vv. 1565-66)

Entonces, ¿por qué quiere contraer matrimonio? La decisión de Erec de entregar su doncella a la reina para que la vista con ricas prendas y lo que le sigue, es decir, la aceptación por parte de la reina de esta exigencia, debe verse, aquí también, como un rito de adopción. De ese modo Erec reanuda una costumbre inquietante, el matrimonio con una princesa, aquí hija espiritual de la reina, su doncella de alcoba. El sistema endogámico encuentra en esta decisión su crítica más fuerte. Durante un intervalo de tiempo, corto a decir verdad, y en el que la novela de Bretaña alcanzó pleno apogeo, el sistema de alianzas matrimonial feudal permaneció suspendido entre la destrucción y el ocaso. Luego, más adelante, limitados a la perfección los roles de cada contrayente, carecerá totalmente de sentido. Los jóvenes apostarán por la aventura para buscar matrimonio. La exogamia se solidifica en estas decisiones. Primero, fue ingenuamente, sin trabas. Unos años más tarde, y el propio Chrétien tuvo que reconocerlo, el impulso amoroso sólo sevirâ para encauzar la ambición de los hombres y la necesidad de estos caballeros sin fortuna de alcanzar un señorío territorial.

El matrimonio de Enide fue un sueño, poético sin duda. Dió 
lugar a una tendencia, que aún perdura en las novelas de evasión y en las otras, por la que un hombre busca descubrir en el fondo oculto de una mujer de aprovincias elementos de fortuna que las eleven al rango de princesas. Erec lo hizo con Enide. Este fue el juego sugerido por Chrétien en 1170 . Unos años más tarde. Andrés, capellán de la corte capeta, sistematizaba este hecho y sugería que el buen matrimonio comienza por la esencialidad del dominio del hombre sobre la mujer. Es preciso que la mujer sea inferior en rango social al hombre. El orden feudal ya no regía. El amor se convirtió entonces en un lejano lamento o en una pura representación mundana ${ }^{25}$.

Final del proceso. Los hombres volvieron a dominar a las mujeres. La práctica matrimonial había cambiado sensiblemente. Pero la revolución no afectó para nada a ese terrible destino de la mujer casada. Máquina de disciplina, sin duda, el matrimonio según los principios de la Iglesia perpetuará por siglos esa subordinación manifiesta. La mujer, encerrada en las brumas de la novela, creyó que un buen matrimonio era su mayor liberación. ¿Lo creyó de verdad? ¿Cómo podemos saberlo si aún no conocemos con precisión lo que pensaban ellas, las damas, las doncellas, e incluso - ¿por qué no? - las princesas, entre sus miradas furtivas, las frunciones de sus gestos, la elegancia de sus vestidos, sus silencios o esa actitud tierna y distante de quien desea algo y no lo dice? La historia de la mujer, aún hoy, está por hacer. El matrimonio de Enide explica la realidad de la institución, pero no la vivencia de quien la sufrió. ¿Cuánto tiempo tendremos que esperar aún para saber algo de lo que dijeron ellas, las princesas?

25 J.E. RUIz DOMÁNEC, El juego del amor como re-presentación del mundo en Andrés el Capellân, Bellaterra, 1979. 